\title{
Bütünleşik Afet Yönetiminde Boyce-Codd Form Yöntemi ile GLIDE İçerikli Veritabanı Oluşturulması
}

\author{
İrfan MACIT*1 \\ ${ }^{1}$ Çukurova Üniversitesi, Mühendislik Mimarlık Fakültesi, Endüstri Mühendisliği Bölümü, \\ Adana
}

Geliş tarihi: 18.01.2016 Kabul tarihi: 22.04.2016

\begin{abstract}
Özet
Gelişen şehir yaşamı afetlerin etkisinin daha fazla hissedilmesine neden olmaktadır. Afetler günlük hayatımızı istem dışı kesintiye uğratan doğa veya insan kaynaklı olaylardır. Nüfus yoğun olan yerleşim yerlerinde yaşayan insanlar afetlerden daha fazla etkilendiğinden afetler karşı mücadele etmenin önemi daha da artmaktadır. Afet öncesinde ve sonrasında değişik amaç ve hedefler içeren faaliyetler yapılmaktadır. Bütünleşik Afet Yönetimi (BAY) afet öncesinde toplanan verilerin afet sonrasında kullanılmasını sağlayan modern afet yönetimi tekniklerindendir. Bu çalışmada afet sonrasında kurtarma ve müdahale faaliyetlerinde kullanılacak bilgilere ait veritabanı tasarımı Boyce-Codd form yöntemi ile MySQL Workbench bilgisayar programı kullanılarak yapılmıştır. Çalışmada kullanılan GLIDE kodlama uluslararası afet tanımlama sistematiğidir. BAY Veritabanında GLIDE kodları tasarıma Kartezyen çarpımı yapacak şekilde eklenmiş ve iki seviyeli (Three-Tiered Layer) yaklaşım ile kullanıcı arabirim tasarımı oluşturulmuştur.
\end{abstract}

Anahtar Kelimeler: Bütünleşik afet yönetimi, Afetlerde bilişim sistemi, Boyce-Codd veritabanı tasarımı

\section{Database Creation in Integrated Disaster Management with Boyce-Codd Form Method Including GLIDE Content}

\begin{abstract}
The more modern city life causes to feel more the effects of disasters. The disasters are involuntary natural or human-oriented events that interrupt our daily lives. Since the population living in high density is more affected by disasters, precautions against the disasters are getting more important. Some activities that include different purposes and goals are done after or before disasters happen. The Integrated Disaster Management (IDM) is one of the modern management techniques that enable use of the data collected in advance in the case of the disaster. In this study, the database related to the to be used in
\end{abstract}

* Yazışmaların yapılacağı yazar: İrfan MACiT, Mühendislik Mimarlkk Fakültesi, Endüstri Mühendisliği Bölümü, Adana.imacit@cu.edu.tr 
rescue and relief operations after the disaster is designed with Boyce-Codd nomal form method in MySQL Workbench database development environment. GLIDE coding used in the study is an international disaster definition systematics. In BAY database, GLIDE code is added to the design by the Cartesian product and a user interface with two-level layer approach is established.

Keywords: Integrated disaster management, Disaster information systems, Boyce-Codd database design

\section{GİRIŞ}

Genel tanımı ile afet günlük hayatımızı istenmeden doğa veya insan kaynaklı olağandışı olaylar ile aniden kesilmesi şekilde tanımlanabilir. Birleşmiş Milletler (BM) tarafindan yapilan tanımda afet "insanlar için fiziksel, ekonomik ve sosyal kayıplara yol açarak aynı zamanda normal yaşamı kesintiye uğratan, ortaya çıktığı bölgedeki insanların kendi başlarına ve kaynakları ile başa çıkamayacakları doğal, insan veya teknolojik kaynaklı durum" olarak tanımlanmaktadır. $\mathrm{Bu}$ tanıma göre afet durumunun oluşabilmesi için birkaç istem dışı etken bir araya gelerek normal yaşantıyı kesintiye uğratmalıdır. $\mathrm{Bu}$ türden bir kesinti mühendislik problemleri açısından talebin aniden yükselmesi, sunulan mal ve hizmetlerin arzının kesintisi, altyapı hizmetlerinin kesintiye uğraması gibi problemleri ortaya çıkarmaktadır (Şekil 1).

Mühendislik problemleri afet öncesinde statik durum problemleri, afet sonrasında ise dinamik mühendislik problemleri olarak sinıflandirılabilir. Afet öncesinde yapılan planlar genellikle belirlenen durumların çeşitli senaryolar altında incelenmesini kapsamaktadır.

Afet sonrasında problemler dinamik olarak değişmektedir. Afet ortaya çıktığında daha önceden belirlenen senaryolar altında yapılan müdahaleler veya planlar genellikle yetersiz kalabilmektedir. $\mathrm{Bu}$ afet problemlerinin belirsiz durumlar altında gerçekleşmesinden kaynaklanmaktadır. - Dünyada ve ülkemizde afet öncesinde ve sonrasında yapılacak faaliyetler hakkında çeşitli çalışmalar yapılmaktadır. Afet yönetimi sınıflandırmasına göre afet

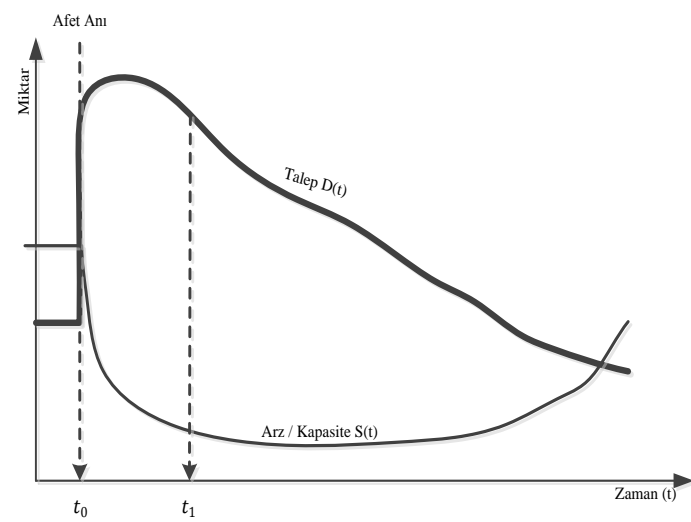

Şekil 1. Mühendislik problemlerinde ortaya çıkan arz/talep fonksiyon değişimi

öncesinde hazırlık ve zarar azaltma, afet sonrasında ise müdahale ve kurtarma aşamaları önem kazanmaktadır. Afet öncesinde yapılan hazırlık çalışmaları beklenen muhtemel durumlar hakkında faaliyet senaryolarını içermektedir. $\mathrm{Bu}$ senaryolara göre bir hastanenin $t_{1}$ anındaki ihtiyaç duyulan yatak kapasitesi veya poliklinik hizmetlerinin beklenen yardım miktarı $H_{t_{1}}$ eşitlik (1) yardımı ile hesaplanabilir. Bu eşitlikte $D(t) \mathrm{t}$ anındaki talep miktarı $S(t)$ ise t anındaki kapasite miktarıdır.

$H_{t_{1}}(t)=\int_{t_{0}}^{t_{1}} D(t) d t-\int_{t_{0}}^{t_{1}} S(t) d t$

Teknolojinin gelişmesi ile daha önceleri sadece doğal kaynaklı olan afetlerin günümüzde insan veya teknoloji kaynaklı olduğu da gözlenmektedir. Daha önceleri doğal sonra insan kaynaklı olan afetlere bu gün artık teknolojik kaynaklı afetler de eklenmiştir. Teknoloji günümüzde afet kaynaklarından birisi olarak görülmesine rağmen aynı zamanda afetin etkilerini azaltmaya yardımcı olmaktadır. Afetlerde afetlerin tiplerine bağlı olarak çok sayıda bilgi üretilmektedir. Bu üretilen bilgilerin afet faaliyetlerinde sağlıklı ve etkin 
kullanılabilmesi için doğru ve zamanında kaydedilmesi ve erişilmesine ihtiyaç vardır. Bilgiler afet öncesinde, afet sirasında veya hemen sonrasında üretilmiş olabilir. Bu bilgiler yardımı ile yapilacak olan afet ile ilgili faaliyetlerin daha etkin yürütülmesi sağlanır. Bahsedilen bu türden bilgilerin üretilmesi, saklanması, güncellenmesi veya silinmesi için çeşitli yöntemler veya araçlar bulunmaktadır. $\mathrm{Bu}$ araçlardan en önemlisi veritabanıdir.

Veritaban1, veri ve/veya bilgileri belirlenen kurallar bütününe göre elektronik ortamda kayıt edilmesi, güncellenmesi ve silinmesi amaci ile elektronik ortamda saklayan kayıt sistemidir. Afet Yönetimi karşılaşılan veya karşılaşılması beklenen afetten en az etkilenmek için yapılan işlem veya eylemler bütünü olarak tanımlanabilir. Veritabanları afet yönetim sürecinde önemli rol oynar. Bilindiği gibi yönetim süreci genel olarak bir birine bağlı karar, planlama, örgütlenme, iletişim ve değerlendirme aşamalarından oluşan ve eylemler bütünü olarak tanımlanabilir [1]

Veritabanlarının ortak bir tasarım ile oluşturulması ve yönetilmesi bilgi kirliliğini de azaltacaktır. Afet sonrasında kimin hangi bilgiyi ne doğrulukta yaydığı belli olmamaktadır. Bu sebepten dolayı kaynağı belli olmayan bilgiler yüzünden etkin bir afet yönetimi yapılamamakta, acil ihtiyaçlar yerine zamanında ulaşamamakta, ulaşan yardım ve malzemeler yanlış veya eksik olabilmektedir. Genellikle medya üzerinden yayılan bilgilerin düzensiz ve denetimsiz olması nedeni ile bu durumlar ile karşılaşılmaktadır. Şüphesiz medyanın afet kurtarma, müdahale ve yardımlarındaki önemi tartışılmazdır. Fakat denetimsiz bilgi akışının olması bilgi kirliliği, bilgilerin tekrarlı olması gibi çok sayıda ve değişik nedenlerden dolayı etkin kurtarma faaliyetleri gerçekleştirilemeyebilir. Bu durumların önlenmesi, etkin bir afet yönetiminin sağlanması için bütünleşik afet yönetiminin oluşturulması ülkeler için gerekli ve zorunlu bir durum almıştır.

\section{LITERATÜR}

Afetler ile ilgili çok sayıda akademik ve uygulama çalışmaları yapılmaktadır. $\mathrm{Bu}$ çalışmalar genellikler afet öncesi ve afet sonrası olarak sinıflandirılmaktadır. $\mathrm{Bu}$ siniflandirmayı afet yönetimi altında incelemek daha güvenilir olarak kabul edilmektedir. Afet yönetim modelleri Afet Yönetimi Çevrimi (AYÇ) ile daha kolay anlaşılabilir [2]. Bu çevrimde afet öncesi ve sonrasında yapılması gerekenler açık olarak belirlenmiştir.

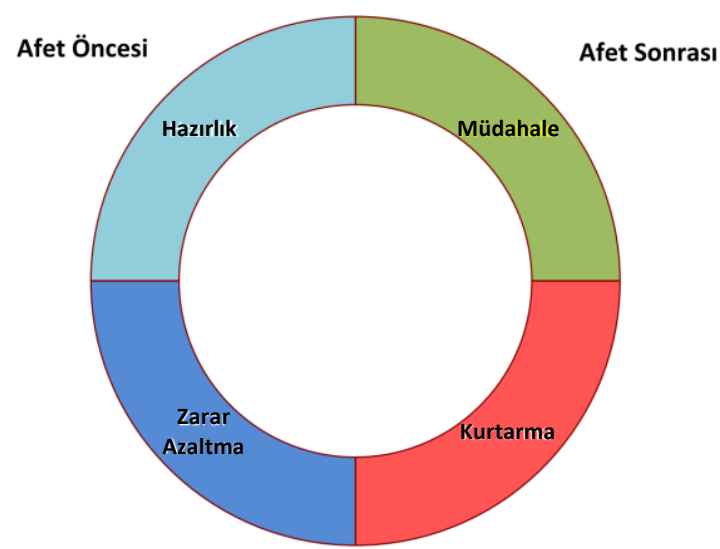

Şekil 3. Afet yönetimi çevrimi [2]

Afet öncesinde yapılan çalışmalarda hazırlık ve zarar azaltma faaliyetlerine, afet sonrasına yönelik yapılan çalışmalarda ise müdahale ve kurtarma faaliyetleri üzerinde yoğunlaşılmaktadır [2]. Yöneylem Araştırması (YA) yaklaşımları kullanılarak afet ve etkileri konusunda çok çeşitli çalışmalar yapılmaktadır. Matematik modelleme yaklaşımları kullanılarak yerleşim problemleri, kaynak atama problemleri, lojistik problemlerini de içeren geniş bir problem alanı bu türden problemlerini çözmeye çalışmaktadır. Afet ve etkileri göz önüne alındığında, bu alanlara benzer ilk çalışmalar yerleşim konusunda yapılan çalışmalardır. Yerleşim problemleri teorik olarak ilk kez 1909 yılında Alfred Weber tarafindan ortaya konmuştur [3]. Bu problemde bir depodan çok sayıdaki müşteriye dağıtım mesafelerinin nasıl en küçükleneceği yazar tarafindan incelenmiştir. Daha sonra Hakimi [4], 1983 yilında otoyolda haberleşme ağı ile polis istasyonlarının yerlerinin belirlenmesi problemi ile literatüre yeni bir çalışma kazandırmıştır. Çok amaçlı yerleşim karar problemleri, çoklu yerleşim problemleri ve dağıtım 
problemleri bunlara örnek olarak gösterilebilir [4]. Temel yerleşim problemleri basit küme kapsama (Basic Set Covering-BSC) problemi olarak da bilinmektedir. $\mathrm{Bu}$ problemde kisitlar eklenince basit yerleşim kapsama modeline dönüşmektedir. Current ve arkadaşları yaptıkları küme kapsama modeli çalışmasında yerleşim problemleri için kesikli şebeke yerleşim (Discrete Network Location Problem) problemlerinin coğrafi analizini göstermişlerdir [5]. Medyan problemleri yerleşim problemlerinde sağlık alanındaki konularda daha fazla rastlanan matematik modeller içerisinde yer almaktadır. Medyan problemlerinde yerleşim yapılacak alanın sayılı $(\mathrm{P})$ adet olması durumunda matematiksel model p-medyan modeli olarak anılır. Bu türden modellerde $\mathrm{d}_{\mathrm{ij}}$ mesafe matrisidir ve $\mathrm{x}_{\mathrm{j}}$ karar değişkenidir.

En küçük $\sum_{j \in J} d_{i j} x_{j} \forall i \in I$

Kisitlar altında:

$\sum_{j \in N_{i}} x_{j}=P \forall i \in I$

$x_{j} \leq y_{i} \forall i \in I$

$x_{j \in\{0,1\} \forall j \in J}$

Burada amaç fonksiyon (2) yerleştirilecek olan P adet tesisin birbirine olan uzaklıklarını minimum olarak bulur. İlk kısıt (3) açılacak olan tesis sayısı kısıtıdır. Balinsky kısıtı olarak bilinen sadece açılacak olan tesislerden hizmet almayı (4) eşitliği sağlar. Son kısıtta (5) karar değişkeninin ikili tam sayı (BI-binary integer) olmasını sağlar. Bu amaç fonksiyonda uzaklık, kapasite ve süre gibi kısıtlar bulunmamaktadır. Tüm talep noktalarının kapsanması öngörülen bu tür modeller Kapasitesiz Tesis Yerleşim Problemleri (Uncapacitated Faclility Location Problem-UCFLP) olarak tanımlanır. $\mathrm{Bu}$ bazı durumlarda istenmeyen yerleşim yerlerinin açılması ve maliyetin artması aylak kapasite kullanımı gibi sorunları da ortaya çıkarmaktadır. İstenmeyen bu durumların ortadan kaldırılması için çeşitli kısıtlar ekleyerek tüm alanların yerine talebin en yüksek olduğu, en az maliyet veya en çok kapasitenin karşılanması gibi problemlere çözüm aranabilir [6]. Basit küme kapsama modelleri ve yerleşim problemleri NPHard problemler olduğu Garey ve Johnson [7] tarafindan incelenmiştir. Yerleşim problemler çok sayıda alanda uygulanıp kullanılmaktadır. Elektrik santrallerinin kurulması Cohon ve ark [8], Acil servis istasyonlarının kurulacak yerlerinin belirlenmesi, Toregas ve arkadaşları [9], itfaiye istasyonlarının yer seçimi Rosing ve arkadaşları [10], araç muayene istasyonlarının yerlerinin belirlenmesi Hodgson ve arkadaşları [11] gibi çok sayıda yerleşim modelleri ile ilgili alanlarda yapılan çalışma bulunmaktadır. Afet konusu başlığı altında bir diğer konu da ülkemizde itfaiye istasyonlarının yerleşim yerlerinin belirlenmesi ile ilgili bazı çalışmalardır. Bu çalışmalar genellikle matematik modelleme yaklaşımları kullanılarak yapılmış çalışmalardır. Çatay ve ark. [12] İstanbul Büyükşehir Belediyesi İtfaiye Daire Başkanlığına bağlı birimlerin tek ve çok dönemli planlama problemini çözmüşlerdir. Yazarların çalışmasında küme kapsama modeline dayanan bir matematiksel model önerilmiştir. Modelin çözümünün zorlaştığ1 duruma ortaya çıktığında yazarlar sezgisel bir çözüm yöntemi önermişlerdir. İstanbul ili için yapılmış olan bir başka çalışmada Aktaş ve ark. [13] itfaiye istasyonlarının yerleşim yerinin belediye sınırlarının tamamını kapsamasının hedeflendiği çalışmada küme kapsama yöntemini kullanmışlardır. Bu çalışmada itfaiye takımlarının vaka müdahale süresinin en çok 5 dakika ile sınırlandırılması da öngörülmüştür. Yazarlar coğrafi bilgi sistemlerinden (CBS) yararlandıkları küme kapsama modeli oluşturmuşlardır.

Dünyada ve ülkemizde afetler ile ilgili çok sayıda çalışmalar yapılmış ve bu çalışmalar günümüzde de araştırılmaya devam etmektedir. Şimdiye kadar yapılan çalışmalarda afet yönetimi yaklaşımını yöneylem araştırması yöntemleri ile çözen modeller bulunmaktadır. Afet yönetimi ve etkilerini içeren problemlerde karşılaşılan çözümü zor modeller bilişim sistemlerinin yardımı ile daha kolay çözülmeye başlanmıştır. Bilişim ve bilgi teknolojileri sistemleri afetin ve etkilerinin çözümünde bilgisayar yazılımları kullanarak matematiksel modellerinin kolaylıkla geliştirilmesini ve çözümünü sağlamaktadır.

Afet yönetiminde bilişim sistemlerinin kullanımı ile ilgili literatürde birebir ilgili çalışmalara rastlanmamaktadır. Genellikle bu çalışmalar coğrafi bilgi sistemleri (CBS), hastane bilgi 
sistemleri (HBS) ve deprem bilgi sistemleri (DBS) anahtar kelimeleri ile rastlanmaktadir. Afet yönetimi ve bilişim sistemlerini beraber inceleyen çalışma alanı Bütünleşik Afet Yönetimi (BAY) yaklaşımdır. BAY yaklaşımı daha yeni bir yaklaşım olması nedeni ile tam olarak standartları oluşmamıştır. Bu yaklaşımın en önemli bileşeni ise bilişim alanında verilerin saklanması, iletilmesi ve işlenmesi alanındaki eksikliktir. BAY veri saklanması konusunda yapılan çalışmalardan en fazla ilgi çeken çalışma Meissner ve ark. yaptığı [14] verilerin belirli bir iletişim ağı da nasıl haberleşeceği ve veri yönetimi ile ilgili olandır.

$\mathrm{Bu}$ çalışmada afet yönetiminde bilişim sistemlerinin kullanımı ve bu yönetim sistemine yardımını içeren bir veritabanı sistemi tasarlanacaktır. Çalışmanın literatüre bilişim sistemleri ile afet yönetiminin arakesiti olarak katkısı olacağı öngörülmektedir.

\section{MATERYAL VE METOT}

Veritabanları bilgi ve belgelerin elektronik ortamlarda belirli bir düzene göre kaydedilmesi, güncellenmesi ve silinmesi işlemlerini gerçekleştiren kayıtlar olarak tanımlanabilir. Verilen bu tanıma göre afet yönetimi açısından veritabanları gerçekleşen olaylara ait verileri istenen veya belirlenen bir düzene göre elektronik ortamda saklayabilirler. Dünyada oluşan afetlerin kayıtlarının belirli bir düzene göre çeşitli organizasyonlar tarafından tutulduğu bilinmektedir. Dünyada ortaya çıkan afetlere ait verilerin CRED (Center for Research on the Epideiology of Disasters) ve FEMA (Federal Emergency Management Agency) tarafindan kaydedildiği ve istatistiklerinin hesaplandığ bilinmektedir. $\mathrm{Bu}$ veriler genellikle ham veri ve bilgilerden oluşturulmakta hükümetler, organizasyonlar ve araştırmacılar tarafından çeşitli amaçlar ile kullanılmaktadır. Görüldüğü gibi afet bilgileri ve afet veri bankası yapilacak olan araştırma ve istatistiklerde oldukça önemlidir. Üretilecek olan afet raporlarında, hava tahminlerinde, deprem erken uyarı sistemlerinde oluşan afetlerin kayıtlarının önemi ortaya çıkmaktadır. Bilişim sistemleri günlük hayatımızın kolaylaştıran bazı işlevleri ile de güvenli olmasına yardımcı olan bilgi ve bilgi işleme sistemleridir. Kurum içi kapalı bilgisayar ağlarında bilgilerin işlenmesi sadece bilgiyi işleyen kurumun kaynakları, bilgi düzeyi, sonuç çıkarma yeteneği ve işleme yeteneği ile sınırlı kalmaktadır. Bu sebepten dolayı afet verilerini elinde tutan kurumların çoğu bu bilgileri diğer kurum ve araştırmacılar ile paylaşarak bu verilerden yararlı bilgiler elde etmeye çalışmaktadır.

\subsection{Afetlerde Bilişim Sistemleri}

Bilişim sistemlerinde verilerin işlenmesi bilgi işleyici bir araç yardımı ile olur Şekil 4. Veri işleme süreci olan bu süreçte veri ham olarak bir elektronik kayıt ortamında tutulmaktadır. Bu kayıt ortamından işlenecek olan veri, hedeflenen bilgi ortamına ve beklenen kurallara göre çeşitli işlemlerden geçirilir. Belirlenen bu kurallara göre işlem gören veri artık hedeflenen kayıt ortamına aktarılmaya hazırlıdır. Aktarılarak işlem gören veri artık bilgi olarak elektronik kayıt ortamına aktarılır veya rapor olarak üretilir.

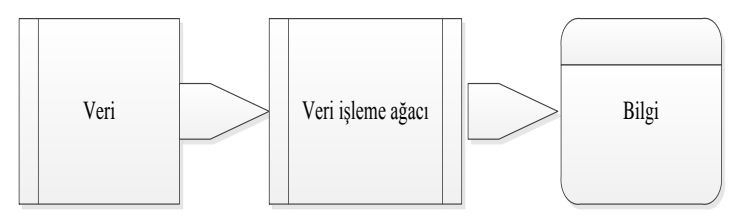

Şekil 4. Veri işleme süreci

Verilerin tutulduğu elektronik kayıt ortamları veritabanı olarak bilinen bilişim sistemleridir. Veriler işlenip bilgi olarak elde edildikten sonra yine aynı sistemler üzerine kaydedilebilir. Afet yönetim sisteminde kayıt edilmesi beklenen veriler afetlerin tipleri, oluştuğu yer bilgisi, saat ve tarihi, afetlerin tiplerine ait özellik bilgileri, etkilediği alanlar, beklenen durum ve sonuçları gibi temel bilgilerdir.

Klasik afet kurtarma faaliyetlerinde, afet çağrısı alındıktan sonra afet ile ilgili bilgilerin toplanması, değerlendirilmesi ve müdahale edilmesi süreçleri kağıt üzerinde alınan kararlara göre yapılmaktadır (Şekil 5). 
Bilişim sistemlerinin afet yönetiminde kullanılması ile afet yönetim sisteminde yeni bir yaklaşım ortaya çıkmıştır. Bütünleşik afet yönetim sistemi olarak bilinen bu sistemde afet ile ilgili veriler bütün bilgisayar ve taşınabilir (mobil) sistemler arasında bilginin iletilmesine olanak sağlamaktadır.

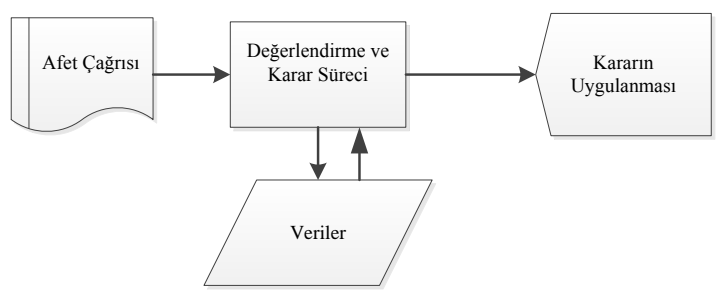

Şekil 5. Klasik afet yönetimi karar süreci

\subsection{Bütünleşik Afet Yönetimi}

BAY, afet öncesinde ve sonrasında ortaya çıkabilecek muhtemel durumlar için senaryoların üretilmesi, alternatif kararlar oluşturulması, karar vericilere daha etkin kararlar almasına yardımcı olma ve afet verilerinin güncel tutulması gibi çok sayıda fonksiyonu yerine getirmektedir. Bu türden fonksiyonları yerine getirirken elektronik ortamlardan, elektronik haberleşme sistemlerinden ve bilişim sistem yaklaşımlarından yararlanmaktadır. Afet ile ilgili bilginin afet yönetim sisteminde öngörülen kurallara göre işlenerek elde edilmesi ile bütünleşik afet yönetim sisteminden bahsedilebilir.

Bütünleşik Afet Yönetiminde verilerin tamamı veya bir kısmı dağıtık veri sistemlerinde tutulabilmektedir. Veritabanında kullanılan dağıtık sistemler verilerin birebir kopyasının başka bir bölgedeki sunucular üzerinde tutulması anlamına gelmektedir. Bu şekilde verilerin dağıtık sistemler üzerinde tutulması verilerin bir bölgedeki afet sonrasinda verilerin kullanılamaz olması durumunda dağıtık alanlardan aynı verinin sağlanmasına olanak tanır. Aynı zamanda verilerin yedeklenmesi görevleri de bu sistem sayesinde sağlanmış olur. Böylece dağıtık sistemlerde veri güvenliği ve sistemin devamlılığı ile ilgili bazı riskler ortadan kaldırılmış olur (Şekil 6).

\subsection{Afet Yönetimi Veritabanı Tasarımı}

Afet yönetiminde kullanılacak veriler hemen ulaşılabilir, güvenli, gerçek zamanlı (güncel), hızlı

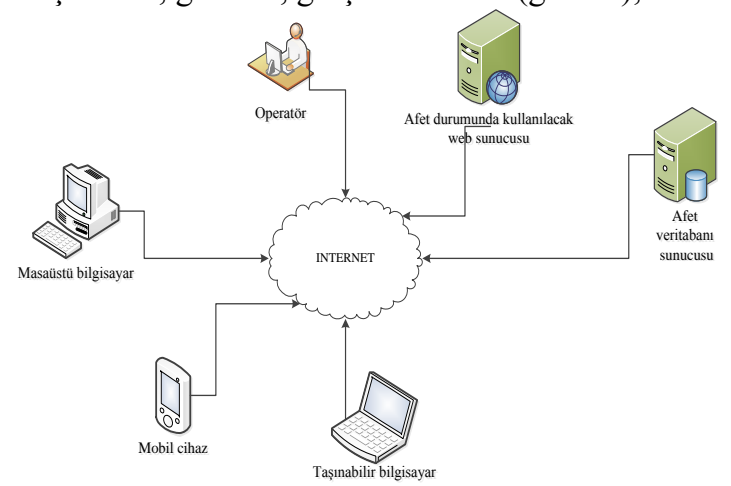

Şekil 6. Bütünleşik afet yönetim sistemi

ve doğru olmalıdır. Bu zorunluluğun nedenlerinde birisi afet sonrasında ihtiyaç olan verilere göre yapilacak planlamaların hataya ihtimal vermeden kullanılmasını sağlamaktır.

Deprem sonrasında yardım ve lojistik faaliyetlerinin organize edilmesi için bölgenin demografik yapısı, iletişim, yollar, bölgeye ait veya yakınındaki bölgelerin makine parkı gibi sayılamayacak kadar çok sayıda verinin tutulmasına ihtiyaç vardır. $\mathrm{Bu}$ verilerin tutulması için tasarımı çok iyi yapılmış, etkin çalışan ve güvenilir veritabanlarına ihtiyaç vardır. Veritabanı tasarımının en önemli özelliklerinden birisi olarak veritabanı normalizasyonu gösterilebilir [15]. Veritabanı normalizasyonu kullanılan veri tabloları üzerinde verilerin tekrarını önlemesinin yanı sıra, veritabanı bütünlüğünü gözönüne alır. Veritabanı tekrarını önlemek için ilișkisel cebir (Relational Algebra) olarak bilinen bir hesaplama yöntemini kullanır. İlişkisel cebir yöntemine göre Çizelge1'de yeralan verilerin bir veritabanı tablosu olduğunu kabul edersek burada ilk sütun EMS 98 Şiddet $\left(D_{1}\right)$ ve ikinci sütun Tanımı $\left(D_{2}\right)$ ise veritabanına ait tablo alanlarının ilişkisel cebri (Cartesian Product);

$R=D_{1} \times D_{2}$ 
eşitlik (1) gibi olur. Verilen bu tabloya göre $D_{1}$ sütunu ile ilişkilendirilecek alanlar arasında çapraz sorgu oluşturulabilecektir. Kartezyen ilişkinin (Cartesian Pruduct) bu türden sorgulamadaki performansı da etkilediği bilinmektedir.

Çizelge 1. EMS 98 Sismik şiddet tanım tablosu

\begin{tabular}{ll}
\hline $\begin{array}{l}\text { EMS 98 } \\
\text { Şiddet }\end{array}$ & Tanım \\
\hline XI & $\begin{array}{l}\text { Hasargörebilirlik sınıfı C olan } \\
\text { çoğu bina 4. derece, birçoğu 5. } \\
\text { derece hasarlıdır }\end{array}$ \\
X & $\begin{array}{l}\text { Hasargörebilirlik sınıfı C olan } \\
\text { çoğu bina 4. derece, birkaçı 5. } \\
\text { derece hasarlıdır }\end{array}$ \\
IX & $\begin{array}{l}\text { Hasargörebilirlik sınıfı C olan } \\
\text { birçok bina 3. derece, birkaçı 4. } \\
\text { derece hasarlıdır }\end{array}$ \\
VIII & $\begin{array}{l}\text { Hasargörebilirlik sınıfı C olan } \\
\text { birçok bina 2. derece, birkaçı 3. } \\
\text { derece hasarlıdır }\end{array}$ \\
\hline VII & $\begin{array}{l}\text { Hasargörebilirlik sınıfı C olan } \\
\text { birkaç bina 2. derece hasarlıdır }\end{array}$ \\
\hline
\end{tabular}

Verilerin $n$ adet tablodan oluştuğunu ve her bir $n$ adet tablonun $\mathrm{m}$ adet sütunu olduğu durumlarda Kartezyen ürün (Cartesian Product) önemi ortaya çıkmaktadır. Bahsedilen Kartezyen ürün kavramına göre veritabanı içerisinde yer alan tüm $\mathrm{n}$ adet tablonun $\mathrm{m}$ adet sütununun bir alt kümesi olması gerekir. Burada önemli olan nokta $n$ adet tablo içerisindeki $\mathrm{m}_{\mathrm{i}}$ 'inci sütunun $\mathrm{m}_{\mathrm{k}}$ sütunundan farklı olması gerekir. Aksi durumda tekrarlı $\mathrm{m}_{\mathrm{i}}=\mathrm{m}_{\mathrm{k}}\{\mathrm{i}<>\mathrm{k}\}$ tekrarlı sütunlarının olması veritabanının performansını olumsuz yönde etkileyecektir. Tekrarlı veri sütunlarının tasarım hatalarını engellemek için Normalize Form tasarımını kullanarak bu istenmeyen hatalardan kurtulabiliriz. BAY veritabanı tasarımı için BoyceCodd Normal form (BCNF) tasarımını kullanılabilir. Boyce-Codd normal form ilişkisel veri şemaları arasında fonksiyonel bağımlılıkları dikkate alır. Sorgulama optimizasyonu yapılacak olan arama sorguları ve işlemlerinin beklenen en iyi zamanda yapılması işlemidir. Veritabanında yapılacak olan aramaların etki olarak tamamlanabilmesi için de çeşitli yöntemler kullanılmaktadır. Etkin veritabanı kullanımı ile doğal afetlerin oluşması veya ortaya çıkmasının hemen ardından müdahale ve kurtarma faaliyetleri kısa sürede en az bilgi gereksinimi ile başlayabilir. Önceden tutulan veriler ile oluşturulacak faaliyet bilgileri kısa süre içerisinde işlenerek ihtiyaç olan mal ve hizmetler planlanabilecektir. Afetlerin veri sinıflandırılmasında GLIDE (Global unique disaster IDEntifier) sistemi dünyada genel kabul görmüş sınıflandırma sistemidir. GLIDE ilk olarak Asya Afet Kurtarma Merkezi (ADRC Asian Disaster Reduction Center) tarafindan önerilmiştir ve yaklaşık 20 uluslararası afet yardım, kurtarma organizasyonu ve araştırma enstitüleri tarafindan kullanılmaktadır. GLIDE veritabanına bir olayın afet olarak kaydedilmesi için üye ülkelerin kendi bölgelerinde oluşan can kaybı ve yaralanma sayılarını belirlemeleri gerekir. Örneğin Japonya'da bir afet kayıt sınırı 5 can kaybı ve en az 100 yaralıdır. Diğer bazı ülkelerde bunu en az 10 can kaybı ve en az 100 yaralı olarak belirlemişlerdir.

Ülkemizde uluslararası afet organizasyonları tarafından taranan ve erişime açık veritabanına rastlanmamaktadır. Uluslararası yardım organizasyonların erişimine açık veritabanı ile paylaşılacak veriler sayesinde ülkemizde afetlere karşı daha etkin mücadele sürdürülebilir. GLIDE sınıflandırma sistemini kullanarak ülkemiz için tasarlanacak veritabanında optimizasyonun sağlanması için Boyce-Codd normal tasarım formlarının kullanılması sağlanmalıdır. BoyceCodd normal form tasarımına göre oluşturulacak veritabanı tabloları arama algoritmaları açısından optimize edildiğinden yardım faaliyetlerinde kullanılacak verilere kolay, hızlı ve doğru bir şekilde ulaşılması sağlanır. Bahsedilen tasarıma göre şablon olarak verilen GLIDE veri formatında ve bağlı tablolarında sınıflandırma, bağlı ağaç yapısı ve veri sözlüğünün optimum olması dolayısı ile hızlı erişim sağlanır.

GLIDE veri formatına göre tanımlama;

\section{AA-BBBB-CCCCCC-DDD-EEE}

şeklinde yapılmaktadır. $\mathrm{Bu}$ tanımlamada AA bölümü afet tanımını göstermektedir. Afet tanımı ise Çizelge 2'de verilmiştir. Tanımlanan bu 
verideki BBBB alanı ise afetin tarihini yıl cinsinden göstermektedir. Verinin üçüncü bölümünde yer alan CCCCCC alanı yıla göre afetin sıra numarasını göstermektedir. Afetin ortaya çıktığı yer ise ülke kodu DDD alanında (ISO-ALPHA 3 Digits) kodları (örn. TUR, Türkiye) [16] ile ifade edilmektedir. Veri formatının son EEE üç karakterlik alanında da ülkeye ait bölge veya şehir kodunu tanımlamaktadır.

Çizelge 2. GLIDE veri kodları [17]

\begin{tabular}{ll}
\hline Afet & Afet Kodlarının Açıklaması \\
\hline Dodu & \\
HW & Kuraklık \\
CW & Sıcak Hava Dalgası \\
TC & Troguk Hava Dalgası Hortum \\
EC & Büyük Tropikal Hortum \\
TO & Kasırga \\
VW & Şiddetli Rüzgâr \\
ST & Şiddetli Yerel Fırtına \\
FL & Sel \\
FF & Ani Sel \\
LS & Yer Kayması /Heyelan \\
AV & Çığ Düşmesi \\
MS & Çamur Kayması \\
VO & Volkan Eriyiği \\
EQ & Deprem \\
FR & Yangın \\
TS & Tsunami \\
SS & Yıldırım Düşmesi \\
EP & Salgın Hastalık \\
IN & Hayvan Kaynaklı Salgın \\
WF & Orman Yangını \\
OT & Diğer Afetler \\
CE & Karmaşı Afet \\
AC & Teknolojik Kaynaklı Afet \\
& \\
\hline
\end{tabular}

BAY afet veritabanı oluştururken afet kodlarına bağlı verilere de dikkat edilmesi önemlidir. Bu verilerden bazıları afetin coğrafi yeri, ilgili açıklama satırı, afet türü, afet bilgisini sağlayan kişi/kurum bilgisi, yardım bilgisi, yardım türü, yardım ekibi, yardım şekli gibi onlarca bilgi içermektedir. Veritabanı tasarlanırken oluşturulan veritabanı içindeki tabloları Kartezyen çarpım
(Cartesian Product) diğer bir değiş ile sorgunun çaprazlanmasına izin vermelidir. Daha sonra oluşturulan sorgulardan raporların çekilmesi sırasında alınan verilerden sınıflandırılmış bilgiler elde edilebilir. $\mathrm{Bu}$ şekilde veri kayıplarının engellenmesi ile afet müdahale sırasında oluşacak kayıpların önüne geçilmiş olur.

\subsection{Veritabanının Oluşturulması}

Bütünleşik afet yönetimi için Linux işletim sistemi üzerinde çalışan. MySql veritabanı tercih edilmiştir. Veritabanı MySql Workbench bilgisayar programı kullanılarak EER diyagramı EK-1'deki gibi geliştirilmiş ve tasarlanan model senkronize edilerek veritabanı oluşturulmuştur.

Veri sözlüğüne uygun olarak tasarlanan EER diyagramında Kartezyen çarpımı testleri yapılmış ve sonuçların EER ilişkilerini doğrular nitelikte olduğu gözlemlenmiştir.

Veritabanı sorgulama arayüzleri (Interface) günümüzde üç katmanlı (Three-Tiered Layer) mimarilerde tercih edilmektedir[18]. Üç katmanlı mimarilerde uygulama sunucusu (application/web server) ile servisi veren veritabanı sunucusu Şekil 7'de görüldüğü gibi ayrı katmanlarda yer almaktadır.

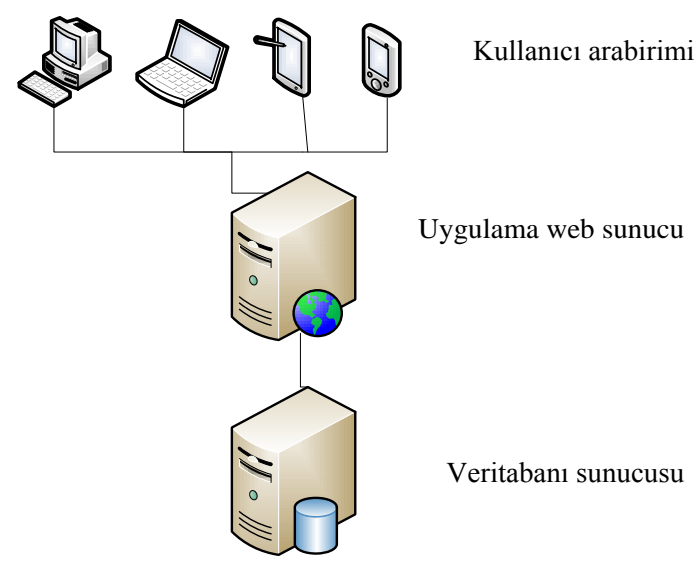

Şekil 7. Üç katmanlı mimari

Oluşturulan Veritabanında kullanıcı tarafından yapılacak sorgulama Kesikli Şebeke Problemleri (DNLP Discrete Network Location Problem) 
olarak bilinen yönteme göre karar vermektedir [5]. Veritabanından alınan verilere göre karar vererek bir karar destek sistemi de çalışmada kullanıcı arabirimi içerisine yerleştirilmiştir. Modelin karar destek sistemi algoritması (Şekil 8) bilinen medyan problemi çözen algoritmayı içermektedir. $\mathrm{Bu}$ algoritmada en kısa yol veya en yakın komşuluk göz önüne alınmıştır. Karar destek sisteminde kullanılan p-medyan modeli çözümü için GAMS matematik programlama çözücüsünden yararlanılmıştır.

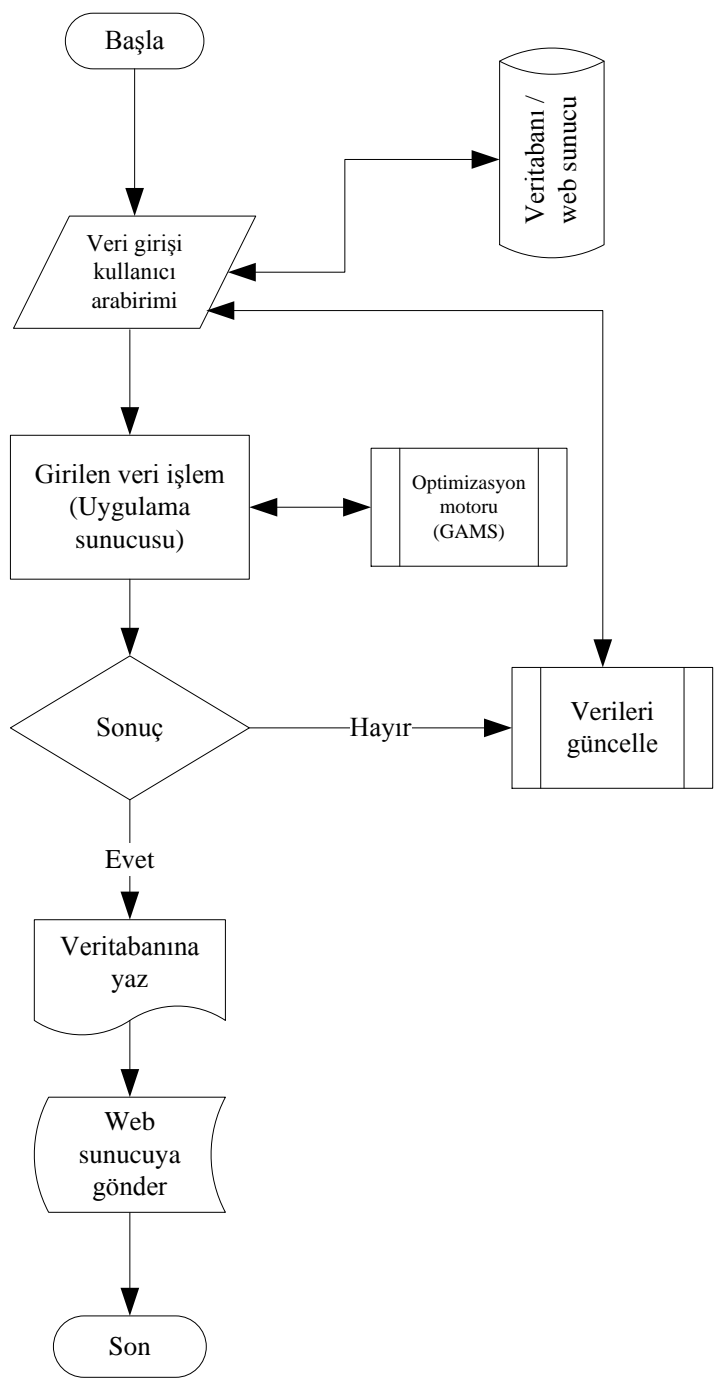

Şekil 8. Karar destek sistemi modeli
Karar Destek Sistemi (KDS) algoritması karar kriterleri veritabanından okunan verileri işleyen ve işlenen verileri kullanıcı arabirimine gönderen bir sistemdir. $\mathrm{Bu}$ sistemde veritabanına yazılan kullanıcı arabirimi veya eş zamanlı veritabanından girilen veriler KDS içerisinde belirlenen algoritmaya göre karar verir ve verilen kararları tasarlanan kullanıcı arabirimine iletir. KDS karar algoritması uygulama sunucusu tarafinda yorumlayıc1 bilgisayar programlama dili ile optimizasyon motoruna gönderdiği verileri alarak beklenen en iyi sonucu test etmektedir. KDS içerisinde çalışan optimizasyon motoru probleme yönelik kurulan p-medyan matematik modeline göre karar vermektedir.

\section{SONUÇ VE ÖNERÍLER}

Çalışmanın sonucunda veritabanına 10000 satırlık veriler yüklenerek tasarlanan sistem 37 gün test edilmiştir. Komutların çalışmasından elde edilen sonuçlara göre oluşturulan grafik Şekil 9'da görülmektedir. Çalışmada daha fazla veriler zaman içerisinde olan olaylardan kaynaklanan sorgulardan kaydedilerek zengin veriler elde edilebilir. Elde edilen daha fazla veriler ile BAY daha etkin yürütülmesi sağlanabilir. Kartezyen çarpımı yapılan tabloların performans analizleri grafiksel olarak anlamlı görülmediğinden çalışmaya sonuçlarında göz önüne alınmamıştır.

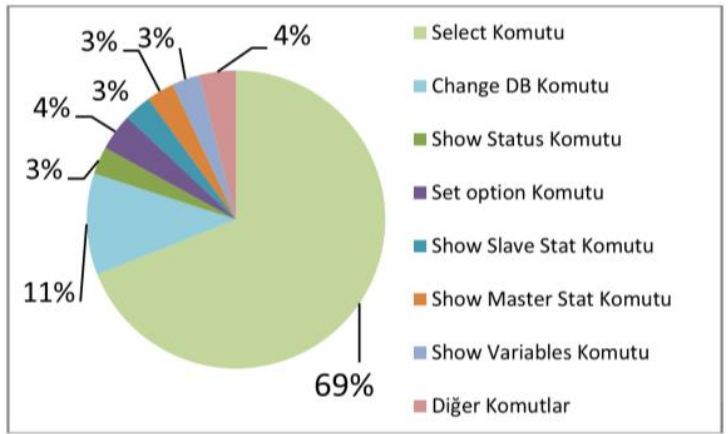

Şekil 9. Veritabanı performans analizi

Afet sonrasında en çok ihtiyaç duyulan doğru ve zamanında gelen eksiksiz bilgidir. Yanlış aktarılan, eksik, gereksiz veya önemsiz bilgiler diğer bilgi işleme birimlerinde olduğu gibi afetlerde de 
gereksiz işlemlere neden olmakta ve faaliyetlerin başarısına etki etmektedir. Bu bilgiler ile afetlere karşı etkin mücadele edilebilir ve mücadelenin başarısı sağlanır. Afet öncesinde önlemler almak sadece afetlere karşı hazırlıklı olmayı sağlamaktadır. Bir afet sonrasında yardım faaliyetleri, kurtarma, müdahale ve lojistik gibi bilginin önemli olduğu faaliyetler de ise bu bilgilerin gereken yer ve zamanda sağlanması hayati önem kazanmaktadır. Bu yüzden afetlerde sağlanacak olan bilginin doğru verilerde işlenmesi ve zamanında sağlanması zorunluluk haline gelmiştir. Bilginin sağlanmasında iyi tasarlanan bir veritabanı ise bütünleşik afet yönetiminin başarısını doğrudan etkilemektedir. Sonuç olarak bütünleşik afet yönetiminde doğru ve zamanında sağlanan bilgiler ile afetlere karşı verilen mücadelede başarı sağlanabilir.

Gelecekte yapılacak olan çalışmalardan beklenenler içerisine zaman içerisinde toplanan daha zengin veriler ile elde edilen sonuçlar ile etkin performans analizlerinin yapılması dahil edilebilir. BAY yeni bir araştırma konusu olması dolayısı ile özellikle bilişim sistemlerini içeren yeni araştırma konuları da bu alana eklenebilir.

\section{TEŞEKKÜR}

$\mathrm{Bu}$ çalışma Çukurova Üniversitesi Bilimsel Araştırmaları Birimi Tarafindan FBA-2015-3249 numaralı proje kapsamında desteklenmiştir.

\section{KAYNAKLAR}

1. Ülgen, H., 1997. İşletmelerde Organizasyon İlkeleri ve Uygulaması, İ.Ü. İşletme Fakültesi, Yayın No:258, İstanbul,

2. Carter, N.W., 2008. Disaster Management A Disaster Manager's Handbook. Asian Development Bank. Manila.

3. Drezner, Z., 1992 A Note on the Weber Location Problem Annals of Operations Research, 40, pp. 153-161.

4. Hakimi, S.L., 1983. On Locating New Facilities in A Competitive Environment. European Journal of Operational Research, Vol. 12, 29-35.
5. Current, J., Schilling, D., 1990. Analysis of Errors due to Demand Data Aggregation in the Set Covering and Maximal Covering LocationProblems Geographical Analysis, 22, 116-126.

6. Daskin, M.S., 1995. Network and Discrete Location: Models, Algorithms, and Applications Wiley \& Sons, New York.

7. Garey, M.R., Johnson, D.S., 1979. Computers and Intractability: A Guide to the Theory of NP-Completeness W. H. Freeman \& Co. New York, NY.

8. Schilling, D., ReVelle, C., Cohon, J., Elzinga, D., 1980. Some Models for Fire Protection Locational Decisions. European Journal of Operational Research, 5, 1 -7.

9. Toregas, C., Swain, R., ReVelle, C., Bergman, O., 1971. The Location of Emergency Service Facilities. Operations Research. Vol. 19, 13631373.

10. Rosing, K., ReVelle, C., Schilling, D., 1999. A Gamma Heuristic for the p-median Problem European Journal of Operational Research, 117 , 522-532.

11. Hodgson, M.J., Rosing, K.E., Zhang, J., 1996. Locating Vehicle Inspection Stations to Protect a Transportation Network Geographical Analysis, 28 , 299-314.

12. Catay, B., 2011. İstanbul'da İtfaiye İstasyonu Yer Seçiminde Risk Faktörüne Dayalı Bir Çoklu Kapsama Yaklaşımı. Endüstri Mühendisliği Dergisi, Vol 22, 33-44.

13. Aktaş, E., Özaydın, Ö., Uluengin, F., Önsel, Ş., Ağaran, B., 2011. İstanbul'da İtfaiye İstasyonu Yerlerinin Seçimi için Yeni Bir Model. Endüstri Mühendisliği, 22 (4), 2-12.

14. Meissner, A., Lukenbach, T., Risse, T., Kriste, T., Kircher, H., 2002. Design Chalnges for Integrated Disaster Management Communicatio and Information Systems. The First IEEE Workshop on Disaster Recovery Networks DIREN2002.

15. Silbershatz, A., Korth, H., Sudarshan, S., 2002. Database System Concept. McGraw-Hill. NY. 4 th. Ed. 1043.

16. ISO Country ALPHA-3 Code List Digits, URL: http://www.nationsonline.org/ oneworld/country_code_list.htm 
17. GLIDE Number Index, URL: http://glidenumber.net/glide/public/search/sear ch.jsp?

18. Elliott, R, Powers, N., Intellex, One-Tier, TwoTier, Three-Tier, A Server: Using Technology to Solve Business Problems, URL:http://www.pacificelectric.com/PacificEle c/Product/whtpap04.htm 
EK 1. Tasarlanan sistemin EER diyagramı ve veri sözlüğü

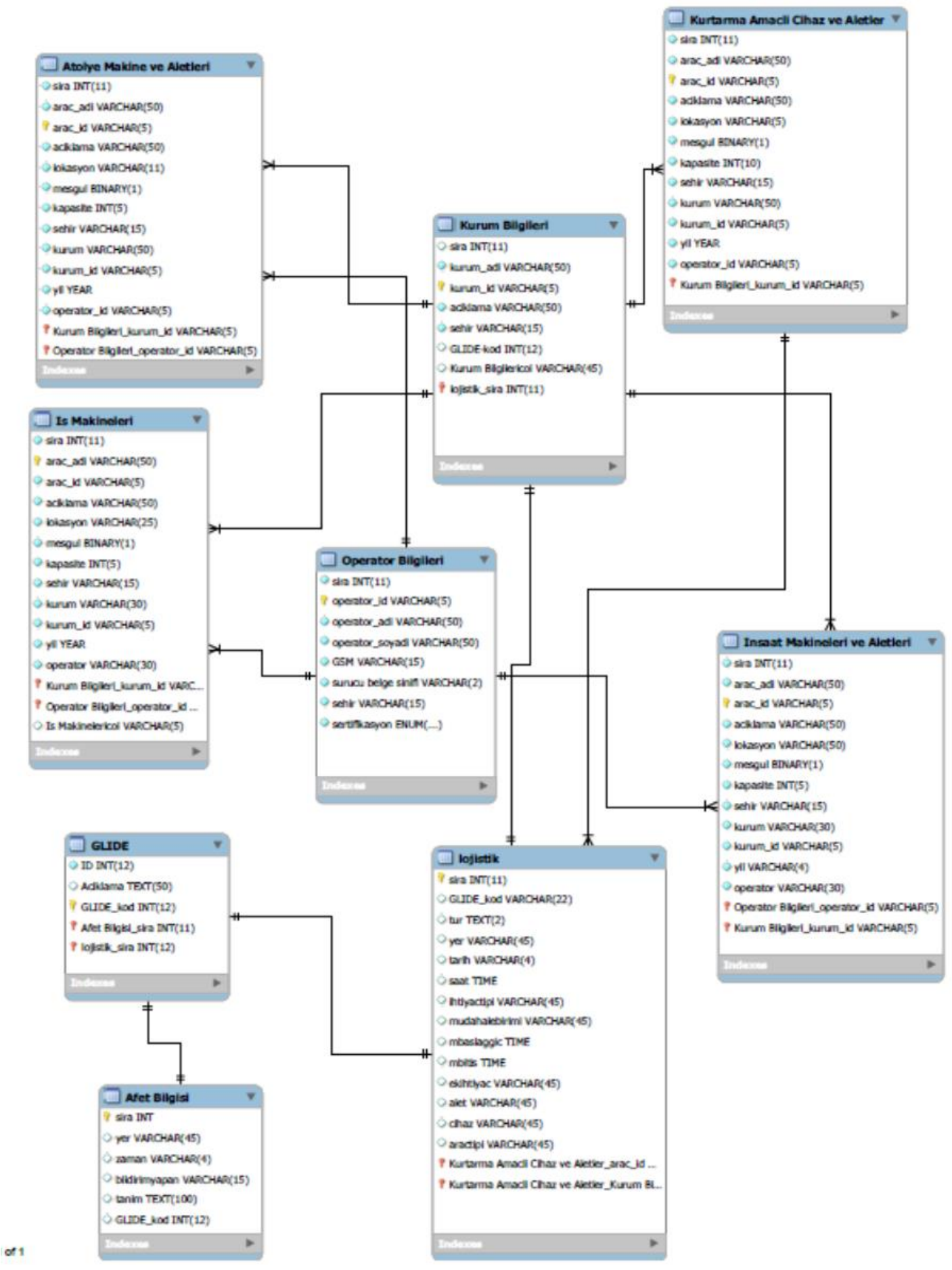

